\title{
Nutritional Status and Body Image Satisfaction among Adolescent Girls
}

\author{
Anju Kayathri S ${ }^{1}$, Aiswarya Mohan², Indujamol $\mathbf{M}^{3}$ \\ ${ }^{1}$ Lecturer, Amrita College of Nursing, Amrita Vishwa Vidyapeetham, Kochi \\ ${ }^{2,3}$ Student, IV Year B.Sc. Nursing, Amrita College of Nursing, Amrita Vishwa Vidyapeetham, Kochi \\ Corresponding Author: Anju Kayathri S
}

\begin{abstract}
Background: Adolescence is a phase of accelerated growth and major physical changes take place in the body. Nutritional status during the crucial period of adolescence could be a potential predictor of body image perception.

Objectives: The study aimed at assessing the nutritional status and body image satisfaction among adolescent girls.

Methods: Descriptive study was conducted among 135 adolescent girls of selected school, Kochi selected through random sampling method. Tools used were structured questionnaire for demographic data, BMI for age growth chart (5-19 years) $\mathrm{Z}$ score according to WHO and nutritional history to assess nutritional status and body image satisfaction was assessed by modified version (SF-14) of Body Shape Questionnaire (BSQ). Data was analyzed using SPSS version.
\end{abstract}

Results: Majority (63.7\%) of them having normal nutritional status, $17.8 \%$ of them were mild thinness, $8.9 \%$ were overweight $7.4 \%$ of them were showing severe thinness and only 2.2 $\%$ of them were obese. Among that majority (57.8\%) had mild concern, $8.9 \%$ of them having moderate concern and $2.2 \%$ of them having marked concern regarding the body image irrespective of their BMI. And also there was highly statistically significant $(\mathrm{p}=.000)$ association between nutritional status and body image satisfaction

Interpretation and Conclusion: Though majority of study groups satisfied about their body image few girls felt moderate to marked concern with their nutritional status. Raising awareness of body image size and increasing body satisfaction with weight status should be established by good receptions of healthy lifestyle among girls.

Key Words: nutritional status, body image satisfaction, adolescent girls

\section{INTRODUCTION}

Adolescence is the second decade of life and a period of expeditious development. It is a time with whisky growth and major physical changes take place in the body. ${ }^{[1]}$ Adolescent constitute about one fifth of the world's population. It is estimated that adolescent girls comprise about $21 \%$ of the total population of India. [2] The term adolescent is extract from the Latin Word Adolescents, which experience a variety of physical, mental and social problems like anxiety, depression, eating disorders, drug abuse, tobacco and alcohol abuse, learning disabilities and malnutrition. [3]

Adolescent girls demanded special heed in their health and nutritional care. Nutrition is usually taken as a outstanding indicator of the health and overall status of adolescence. Malnutrition is often cited as the major reason for the detain in the onset of puberty in Indian adolescents. Socioeconomic status, food habits, heredity and environment also affect their nutritional status to a great extent. ${ }^{[6]}$ The NFHS-4 reported that the prevalence of anemia was high up (54\%) among adolescents (ages 15-19) compared with other group of women in reproductive age group. ${ }^{\text {[7] }}$ The last two decades have witnessed an increase 
in health care costs due to obesity and associated issues among children and adolescents. $^{[8]}$

Adolescent eating is conceptualized as a function of individual and environmental influences. The search for identity, the struggle for independence and acceptance, and worry about appearance, tend to have a great influence on lifestyle, eating patterns and food intake among adolescents (Spear, 2002) risk of malnutrition and chronic diseases in the future. Thus, dietary decisions made in adolescence may have perpetual health implications. Awareness on healthy eating habits will definitely make the adolescents aware about their health and its significance in future living.A study in Nepalese school children exhibited that fast foods (ready to eat snacks, chips etc.) were preferred by more than two-third of adolescents. ${ }^{[9]}$ Many hurdles prevent young people from practicing healthy lifestyles. ${ }^{[10]}$ The meal pattern of adolescents becomes more disorganized, and they tend to miss their meals at home as they get older, often omit breakfast.

Study conducted in Kochi, Kerala showed that $8.6 \%$ school gong adolescents skipped breakfast almost daily due to lack of time (20\%), conscious about body image $(10 \%)$, not hungry in the morning (4\%), don't like breakfast foods $(2 \%)^{[11]}$. Some dietary patterns like snacking, usually on energy dense foods, wide use of fast foods that are low in iron, calcium, riboflavin, vitamin A, folic acid and fibers, low consumption of fruits and vegetables and defective dieting are more common among the adolescents of industrialized countries. [12]

Body image refers to the compound psychological experience of embodiment, especially but not exclusively on one's physical appearances. Body image encompasses one's body related selfperceptions and frame of mind which includes thoughts, beliefs, feelings and behaviors. The influence of body image or the ideal body is a delicate issue which requires prompt attention as dissatisfaction with one's body is often seen as a correlate of eating disorders especially among Women. This has been manifested by the high prevalence of eating disorders in groups in which there is an increased emphasis on maintaining a thin, ideal body. [13] Excessive concern about body image, body image misconception are leading to dissatisfaction, disrupted eating patterns, affecting the nutritional status and also leading to depression and anxiety disorders.

This concept of body image has been less explored in Indian context, principally among young girls. Slim figure is socially admissible body size among female adolescent. Consequently, there is widespread preoccupation with weight control to attain such a body size, some of which are very dangerous among adolescent girls. ${ }^{[14]}$ Thus this has conducted to assess the nutritional status and body image satisfaction of adolescent girls in selected school of Kochi.

\section{MATERIALS AND METHODS}

The study was a descriptive study to identify the nutritional status and body image satisfaction among adolescent girls. The study was conducted among 135 students of selected higher secondary school, Kochi, who were mentally fit and had no debilitating illness. The sample was collected through simple random sampling. Ethical clearance from the Institutional Review Board, permission from the principal of selected higher secondary school, and informed consent was collected from each study subject and from their parents prior to collection. Data collection was done in a period of January 2020.

Data was collected using three questionnaires including structured questionnaire for collecting demographic data, Nutritional status was assessed by obtaining height, weight and BMI. Height was measured inch tape and weight was measured using digital weighing machine to the nearest to $0.1 \mathrm{~kg}$. BMI was calculated by, BMI for age growth chart (5-19 years) $\mathrm{Z}$ 
score according to $\mathrm{WHO}$ and interpreted as $<-3 S D$ z score (Severe thinness), -3SD to -2 SD (Mild thinness) $>-2 S D$ to $<0.99$ SD (Normal),1.00SD to 1.99 SD (Overweight) and $>=2$ SD (Obese).

Structured questionnaire to collect nutritional history which include questions like type of diet, meal pattern, intake of vitamin supplements, type of influence in reducing weight, measures chosen to reduce weight, food allergy, change in body weight, perception regarding the body image. Body image satisfaction was assessed by Modified Version (SF-14) of Body Shape Questionnaire (BSQ) which included question to be rated by 6 point Likert scale which includes 14 questions and interpreted as Maximum score is 84 . And minimum score is 14. And score is classified as $<21$ - No concern with body shape, 21-41- mild concern with body shape, 42-62- moderate concern with body shape, >63- marked concern with body shape

\section{STASTICAL ANALYSIS}

Data was analyzed using descriptive and inferential statistics. Frequency and percentage and Chi square test was done to determine the association between the body image satisfaction and selected socio demographic variables, association between nutritional status and socio demographic variables and association between nutritional status and body image satisfaction.

\section{RESULTS}

The study was conducted among 135 adolescent girls from $13-17$ years. Results revealed that majority $(54.1 \%)$ were from higher secondary section. Among that $75.6 \%$ belongs to joint family out of that $51.1 \%$ of students were the second child in the family and also $73.3 \%$ of them having one sibling. Regarding the fathers level of job $78.5 \%$ are self-employed and $45.9 \%$ of their mothers were housewife.
Table I: Frequency and percentage distribution of Nutritional Status (Z Score), $(n=135)$

\begin{tabular}{|l|l|l|l|}
\hline Sl.No & Standard deviation & Frequency & Percentage \\
\hline 1 & $<-3$ SD (Severe thinness) & 10 & 7.4 \\
\hline 2 & $\begin{array}{l}-3 \text { SD to -2SD (Mild } \\
\text { thinness) }\end{array}$ & 24 & 17.8 \\
\hline 3 & $\begin{array}{l}-2 \text { SD to <0.099SD } \\
\text { (Normal) }\end{array}$ & 86 & 63.7 \\
\hline 4 & $\begin{array}{l}1 \mathrm{SD} \text { to 1.99 SD } \\
\text { (Overweight) }\end{array}$ & 32 & 8.9 \\
\hline 5 & $>=2 \mathrm{SD}$ (Obese) & 2.2 \\
\hline
\end{tabular}

Table II: Frequency and distribution variables based on nutritional history, $\mathrm{n}=135$

\begin{tabular}{|c|c|c|c|}
\hline Sl.no & Variables & Frequency & Percentage \\
\hline 1 & \multicolumn{3}{|l|}{ Type Of Diet } \\
\hline $\mathrm{a}$ & Vegetarian & 9 & $6.7 \%$ \\
\hline $\mathrm{b}$ & Non vegetarian & 126 & $93.3 \%$ \\
\hline 2 & \multicolumn{3}{|l|}{ Number of meals } \\
\hline $\mathrm{a}$ & 1 & 1 & $.7 \%$ \\
\hline $\mathrm{b}$ & 2 & 20 & $14.8 \%$ \\
\hline $\mathrm{c}$ & 2or more & 114 & $84.4 \%$ \\
\hline 3 & \multicolumn{3}{|l|}{ Type of Food } \\
\hline $\mathrm{a}$ & Homely food & 122 & $90.4 \%$ \\
\hline $\mathrm{b}$ & Fast food & 5 & $3.7 \%$ \\
\hline $\mathrm{c}$ & Others & 8 & $5.9 \%$ \\
\hline 4 & \multicolumn{3}{|l|}{ Measures to reduce weight } \\
\hline $\mathrm{a}$ & Exercise & 51 & $37.8 \%$ \\
\hline $\mathrm{b}$ & Skip food & 33 & $24.4 \%$ \\
\hline $\mathrm{c}$ & Medication & 2 & $1.5 \%$ \\
\hline $\mathrm{d}$ & Not applicable & 49 & $36.3 \%$ \\
\hline 5 & \multicolumn{3}{|c|}{ Measures to choose When Concerned } \\
\hline $\mathrm{a}$ & Consult doctor & 22 & $16.3 \%$ \\
\hline $\mathrm{b}$ & $\begin{array}{l}\text { Follow advice of family } \\
\text { members }\end{array}$ & 40 & $29.6 \%$ \\
\hline $\mathrm{c}$ & Diet modification & 38 & $28.1 \%$ \\
\hline $\mathrm{d}$ & Not concerned & 35 & $25.9 \%$ \\
\hline 6 & \multicolumn{3}{|l|}{ Perception of body image } \\
\hline $\mathrm{a}$ & Lean & 39 & $28.9 \%$ \\
\hline $\mathrm{b}$ & Normal & 81 & $60.0 \%$ \\
\hline $\mathrm{c}$ & Overweight & 15 & $11.1 \%$ \\
\hline 7 & \multicolumn{3}{|c|}{ Type of influence to change weight } \\
\hline $\mathrm{a}$ & Mass media & 26 & $19.3 \%$ \\
\hline $\mathrm{b}$ & Peer groups & 23 & $17.0 \%$ \\
\hline $\mathrm{c}$ & Family members & 53 & $39.3 \%$ \\
\hline $\mathrm{d}$ & Not applicable & 33 & $24.4 \%$ \\
\hline 8 & Acute Illness & & \\
\hline $\mathrm{a}$ & Yes & 53 & $39.3 \%$ \\
\hline $\mathrm{b}$ & No & 82 & $60.7 \%$ \\
\hline 9 & \multicolumn{3}{|l|}{ Change In Appetite } \\
\hline $\mathrm{a}$ & Yes & 24 & $17.8 \%$ \\
\hline $\mathrm{b}$ & No & 111 & $82.2 \%$ \\
\hline 10 & \multicolumn{3}{|l|}{ Food Allergy } \\
\hline $\mathrm{a}$ & Yes & 23 & $17.0 \%$ \\
\hline $\mathrm{b}$ & No & 112 & $83.0 \%$ \\
\hline 11 & \multicolumn{3}{|l|}{ Vitamin Supplements } \\
\hline $\mathrm{a}$ & Yes & 61 & $45.2 \%$ \\
\hline $\mathrm{b}$ & No & 73 & $54.1 \%$ \\
\hline 12 & \multicolumn{3}{|l|}{ Recent weight change } \\
\hline $\mathrm{a}$ & Yes & 29 & $21.5 \%$ \\
\hline $\mathrm{b}$ & No & 106 & $78.5 \%$ \\
\hline 13. & \multicolumn{3}{|l|}{ Food avoided for medication } \\
\hline $\mathrm{a}$ & Yes & 57 & $42.2 \%$ \\
\hline $\mathrm{b}$ & No & 78 & $57.8 \%$ \\
\hline
\end{tabular}

Nutritional status was assessed by Body Mass Index according to WHO- BMI for age growth chart (5-19 years) $\mathrm{Z}$ score 
and nutritional history. Results revealed that majority of girls $(63.7 \%)$ were normal weight, $8.9 \%$ were overweight, and $17.8 \%$ having mild thinness, $7.4 \%$ of were severe thinness and only $2.2 \%$ of them were obese.

Table 1 shows that $7.4 \%$ of students having severe thinness, $17.8 \%$ having mild thinness, $63.7 \%$ were normal weight, $8.9 \%$ were overweight and only $2.2 \%$ of them were obese.

Regarding nutritional history majority of girls $(93.5 \%)$ were non vegetarian. In that $84.4 \%$ were consuming more than 2 meals per day and also majority (90.4\%) used to have homely food. $17.8 \%$ were felt change in their appetite for the past six months. About $83 \%$ were having allergy to some of foods and $42.5 \%$ were using some vitamin supplements along with their diet.

Table II denotes that majority of girls $(93.5 \%)$ were non vegetarian. In that $84.4 \%$ were consuming more than 2 meals per day and also majority $(90.4 \%)$ used to have homely food. $17.8 \%$ were felt change in their appetite for the past six months, $28.9 \%$ were perceived as lean and only $11.1 \%$ perceived as overweight and also $21.5 \%$ reported recent weight change for the past 6 months among that $37.8 \%$ were doing exercise to reduce weight, $24.4 \%$ were skipping meals

Satisfaction about body image on weight status revealed that majority $(57.8 \%)$ have mild concern, $8.9 \%$ were moderate concern about their body image in relation to their body weight.(Figure 1)

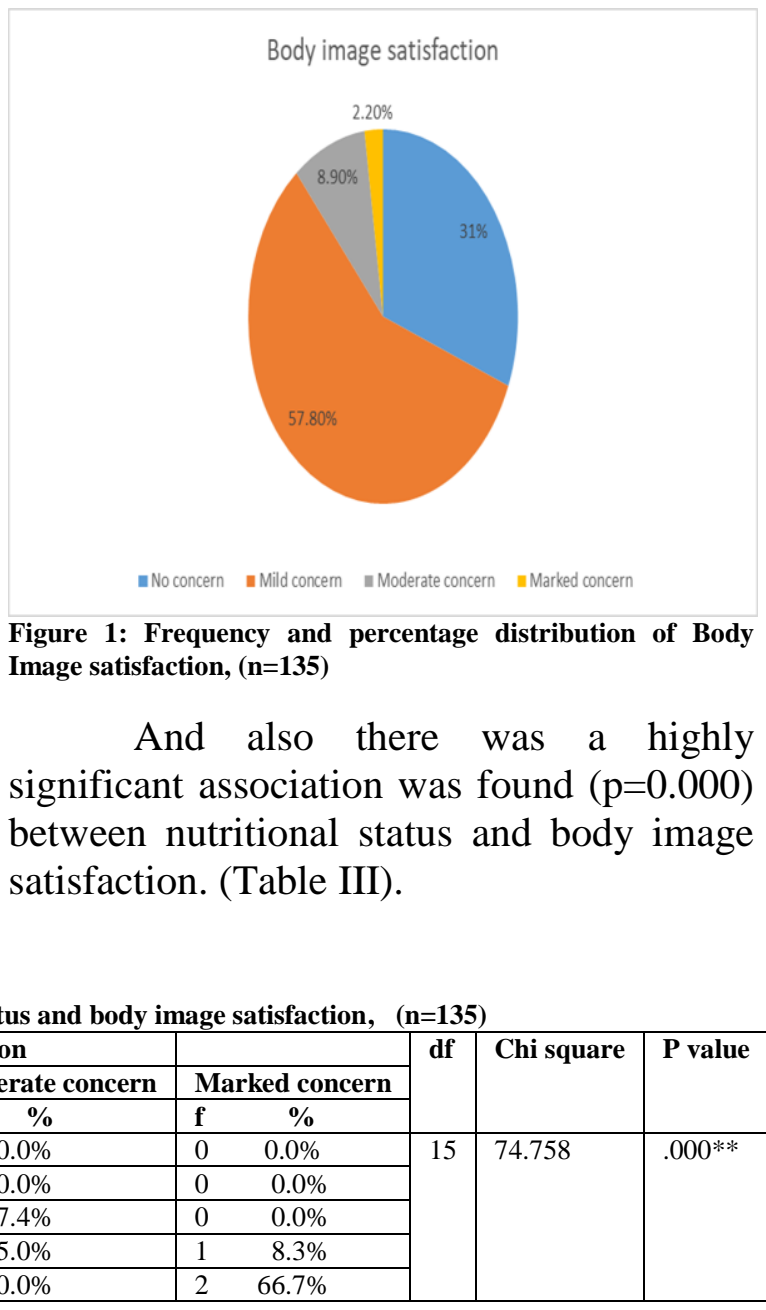

Figure 1: Frequency and percentage distribution of Body Image satisfaction, $(\mathrm{n}=135)$

And also there was a highly significant association was found $(p=0.000)$ between nutritional status and body image satisfaction. (Table III).

Table III: Association between nutritional status and body image satisfaction, $\quad(n=135)$

\begin{tabular}{|c|c|c|c|c|c|c|c|}
\hline \multirow{3}{*}{$\begin{array}{l}\text { Nutritional status } \\
\text { (Z SCORE) }\end{array}$} & \multicolumn{3}{|c|}{ Body Image Satisfaction } & & \multirow[t]{3}{*}{ df } & \multirow[t]{3}{*}{ Chi square } & \multirow[t]{3}{*}{ P value } \\
\hline & No concern & Mild concern & Moderate concern & Marked concern & & & \\
\hline & $\%$ & $\%$ & $\%$ & $\%$ & & & \\
\hline$<-3$ SD Sever thinness & $20.0 \%$ & $70.0 \%$ & $1 \quad 10.0 \%$ & $0.0 \%$ & 15 & 74.758 & $.000 * *$ \\
\hline -3SD to -2SD Mild thinness & $10 \quad 41.7 \%$ & $1458.3 \%$ & $0.0 \%$ & $0.0 \%$ & & & \\
\hline$>-2$ SD to $<0.099$ SD Normal & $18 \quad 33.3 \%$ & $3259.3 \%$ & $7.4 \%$ & $0.0 \%$ & & & \\
\hline 1.00SD to $1.99 \mathrm{SD}$ Overweight & $0.0 \%$ & $8 \quad 66.7 \%$ & $3 \quad 25.0 \%$ & $8.3 \%$ & & & \\
\hline$<2$ SD Obese & $33.3 \%$ & $0.0 \%$ & $0.0 \%$ & $66.7 \%$ & & & \\
\hline
\end{tabular}

Table IV: Association between body image satisfaction and selected socio demographic variables. $(n=135)$

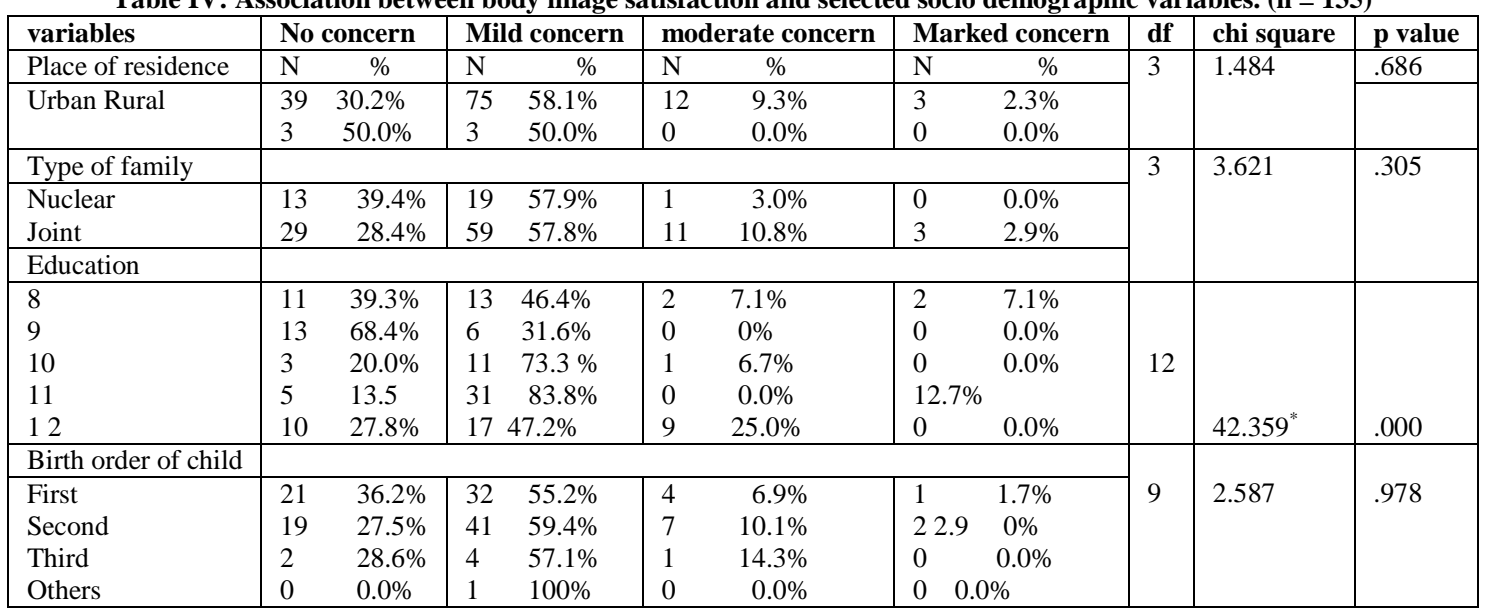


Table depicts that highly statistical signification association, $\quad(\mathrm{p}=0.000 * *)$ between nutritional status and body image satisfaction .Results also revealed that nutritional status is not significantly associated with socio demographic variables ( $\mathrm{p}>0.05$ ) but body image satisfaction is significantly associated with their level of education and not having association with other socio demographic variables. (Table IV)

Hence, table depicts that there is highly statistical significant association was found between body image satisfaction and level of education $(\mathrm{p}=0.000)$.

\section{DISCUSSION}

This study has evaluated the association between nutritional status and body image satisfaction and in school students among adolescent girls. Among 135 study participants nutritional status assessed by $\mathrm{z}$ score showed that $(63.7 \%)$ were normal weight, $8.9 \%$ were overweight, $17.8 \%$ having mild thinness, $2.2 \%$ of them were obese and only $7.4 \%$ of were severe thinness and it is congruent with the findings of similar study conducted to assess prevalence of underweight, stunting and thinness of rural adolescents school girls showed that overall rate of under nutrition was $33.13 \%$, while stunting was $28.06 \%$ and $17.92 \%$ thinness was respectively. ${ }^{[16]}$

The present study also found that majority $(60 \%)$ perceived their body image as normal whereas $28.9 \%$ were perceived as lean and only $11.1 \%$ perceived as overweight and also $21.5 \%$ reported recent weight change for the past 6 months among that $37.8 \%$ were doing exercise to reduce weight, $24.4 \%$ were skipping meals $.29 .6 \%$ were following advice of family members in weight management, $28.1 \%$ were doing dietary modification, $16.3 \%$ were consulting doctor, and $25.9 \%$ were not concern about any of the measures. This finding is supported by another study conducted at north Karnataka shows that $10.7 \%$ of normal weight girls were trying to increase their weight by increasing quantity and frequency of meals and $16.7 \%$ girls who perceived to be overweight, skipped meals to reduce weight. ${ }^{[15]}$

The current study depicted that majority $(57.8 \%)$ have mild concern, $8.9 \%$ were moderate concern about their body image in relation to their body weight which shows that mild to moderate dissatisfaction about their body image but $2.2 \%$ are showing marked concern about their body image which is supported by similar study $50.5 \%$ adolescents were having normal BMI and were not concerned with their shape, also $60.69 \%$ adolescents were in healthy fitness zone and were not concerned. $15.25 \%$ population with normal BMI showed concern about their body image. ${ }^{[17]}$ And also there was highly statistically significant $(\mathrm{p}=.000)$ association between nutritional status and body image satisfaction which is supported with another study found that Association was found between body image dissatisfaction and nutritional status. ${ }^{[1]}$

In this present study found that there was no statistically significant association with nutritional status and body image satisfaction $(\mathrm{P}>0.05)$ except in level of education $(\mathrm{p}=0.000)$ with body image satisfaction and it is congruent with another study shows that socio-demographic parameters weren't found to have statistically significant association with nutritional status and body image dissatisfaction $(\mathrm{P}>0.05){ }^{[1]}$

\section{CONCLUSION}

The present study concluded that majority of study groups satisfied about their body image few girls felt moderate to marked concern with their nutritional status. As having a distorted body image may lead to negative effects such as unhealthy eating habits and disordered eating behaviors it is recommended that appropriate educational awareness of body image size and increasing body satisfaction with weight status should be established by good receptions of healthy lifestyle among girls. 


\section{ACKNOWLEDGMENT}

The researcher feels thankful to all the study participants and principal of the school who gave permission and support all through the study

Ethical Approval: Approved by the Institutional Ethics Committee

Conflict of Interest: None

Source of Funding: None

\section{REFERENCES}

1. Pokhrel S, Acharya B, Adhikari C. Nutritional status and body image dissatisfaction among adolescent girls in Kaski district, Nepal. International Journal of Health Sciences and Research, 5 (6), 462. 2015;469.

2. Sivagurunathan C, Umadevi R, Rama R, et al. Adolescent health: present status and its related programmes in India. Are we in the right direction?. Journal of clinical and diagnostic research: JCDR. 2015 Mar;9(3): LE01

3. Shaji G, Joseph NC, Mathu A et al. A study to assess the knowledge and attitude of adolescents towards obesity in a private school in Thrissur district Kerala, India. IJCMPH. 2019; 6(7).

4. Sridhar D, Gauthami N. Nutritional status of adolescent tribal girls: A community based study. MedPulse International Journal of Community Medicine. 2017 Oct;4(1):1-4..

5. Athira C, Maneesh P. Adoloscence girls development and ICDS: A case study of anganwadi centres in Kannur District, Kerala. Indian Journal of Economics and Development. 2016 Feb 1;4(2):1-5.

6. Ramya R, Thomas A. Nutritional Status And Dietary Pattern Of Adolescent Girls Of Kottayam Taluk. International Journal of Advanced Research. 2015;3(4):949-55.

7. National family health survey. pub.gov.in ,2019.

8. Raj M, Kumar RK. Obesity in children \& adolescents. The Indian journal of medical research. 2010 Nov;132(5):598..

9. Singh JP, Kariwal P, Gupta SB, et al,. Assessment of nutritional status among adolescents: a hospital based cross sectional study. Int J Res Med Sci. 2014 May;2(2): 620-4.

10. Tomy C, Fathima FN, Mathew SS, et al. Barriers to healthy lifestyle among collegegoing students in a selected college in Bengaluru Urban district. Indian journal of community medicine: official publication of Indian Association of Preventive \& Social Medicine. 2019 Oct;44(Suppl 1): S54.

11. Kurien AJ, Rejiv A, Premarajan A,et al. Breakfast-eating habits of school-going adolescents in Kochi, Kerala, India. The National medical journal of India. 2018 May 1;31(3):188.

12. World Health Organization. Nutrition in adolescence: issues and challenges for the health sector: issues in adolescent health and development.

13. Leena M V, Manoj T. I., Body Image and Self-Esteem: Differences and Relationship among Females Belonging to Varied Vocations, 26 International Journal of Physical Education, Health \& Sports Sciences volume: 05, issue: 01, March 2016 ,26- 27.

14. Rajika K, Gayatri R. A Correlational Study On Body Image and Self Esteem Among Employees of Multinational Corporations. Journal of Global Biosciences. 2019;8(5): 6236-56.

15. Rashmi BM, Patil SS, Angadi MM,et al,. A cross-sectional study of the pattern of body image perception among female students of BBM college in Vijayapur, North Karnataka. Journal of clinical and diagnostic research: JCDR. 2016 Jul;10(7):LC05.

16. Maiti S, Chatterjee K, Ali KM,et al. A study of anthropometric variables on growth and nutritional status of rural adolescent school girls in Paschim Medinipur, West Bengal. IJCR. 2011; 3(7); 36-40

17. Ekbote V, Shimpi A, Rairikar S,et al. Perception of body image to fat content in adolescent girls and boys. Journal Youth Adolescent Health. 2017;4(2):30-3.

How to cite this article: Anju Kayathri S, Mohan A, Indujamol M. Nutritional status and body image satisfaction among adolescent girls. International Journal of Research and Review. 2021; 8(10): 77-82. DOI: https://doi.org/10. 52403/ijrr.20211012 